\title{
A Case of a Novel Mutant Vasopressin Receptor-Dependent Nephrogenic Diabetes Insipidus with Bilateral Non-Obstructive Hydronephrosis in a Middle Aged Man \\ - Differentiation from Aquaporin-Dependent Nephrogenic Diabetes Insipidus by the Response of Factor VIII and von Willebrand Factor to 1-Deamino-8-D-Arginine Vasopressin Administration -
}

\author{
MASASHI MIYAKOSHI, KYUZI KAMOI, SHINICHI UCHIDA* AND SEI SASAKI* \\ The Department of Internal Medicine, Division of Endocrine and Metabolism, Nagaoka Red Cross Hospital, Nagaoka Niigata \\ 940-2085, Japan \\ *The Department of Homeostasis Medicine and Nephrology, Tokyo Medical and Dental University, Tokyo 113-8519, Japan
}

\begin{abstract}
We describe a case of a novel mutant vasopressin 2 receptor (V2R)-dependent nephrogenic diabetes insipidus (NDI) with bilateral non-obstructive hydronephrosis in a middle aged man. This could be distinguished from aquaporin 2 (AQP2)-dependent NDI by the response of factor VIII and von Willebrand factor (vWF) to 1-deamino-8-D-arginine vasopressin (DDAVP) administration. A 47-year-old man was admitted to hospital because of polyuria, which had been present from infancy and was suspected of causing non-obstructive hydronephrosis. His mother's father, the older brother of his mother and his second daughter also all had polyuria. Sodium concentration, osmolality and vasopressin in blood were high, while sodium concentration and osmolality in urine were low. There were no changes in urine osmolality, factor VIII and VWF in response to DDAVP infusion. Neither was heart rate, diastolic blood pressure nor facial flushing affected. These findings suggested this case was V2R-dependent NDI rather than AQP2-dependent NDI. Molecular genetic analysis demonstrated that the patient had a V2R missense mutation involving a substitution of cysteine for arginine at position 104 (R104C) located in the first extracellular loop of the V2R. It was also found that the patient's mother and his second daughter were heterozygous for this R104C mutation.
\end{abstract}

Key words: AVPR gene, Nephrogenic diabetes insipidus, DDAVP, factor VIII and von Willebrand factor (vWF)

(Endocrine Journal 50: 809-814, 2003)

Nephrogenic diabetes insipidus (NDI) is a kidney disorder characterized by the kidney's inability to respond to the antidiuretic hormone, arginine vasopressin (AVP) [1]. Up to $90 \%$ of inherited NDI is caused by mutations of the AVP receptor 2 gene (V2R). The remaining cases are the result of mutations of the aquaporin 2 (AQP2) gene or other unknown disturbances [1]. Although each type of inherited

Received: December 9, 2002

Accepted: August 18, 2003

Correspondence to: Dr. Kyuzi KAMOI, the Department of Internal Medicine, Nagaoka Red Cross Hospital, 297-1 Terajimamachi, Nagaoka, Niigata, 940-2085, Japan
NDI has a different genetic origin, the symptoms are identical [1-8].

How do we differentiate these types of disorders by clinical examination? Administering 1-deamino-8Darginine vasopressin (DDAVP), and then measuring responses occurring outside the kidney, such as changes in heart rate, diastolic blood pressure, facial flushing, tissue-type plasminogen activator antigen (tPA) and factor VIII and von Willebrand factor (vWF) [1-8], is one way that clinicians have of distinguishing between NDI caused by mutant V2R genes and by mutant AQP2 genes. The patient with NDI caused by mutant AQP2 genes will show responses to DDAVP that take place outside the kidney, while the patient 
whose NDI is the result of mutated V2R genes will not [1-8].

Recently, Inaba et al. reported a patient with NDI caused by a novel mutant VR2 with substitution of cysteine for arginine-104 (R104C) diagnosed at middle age [9]. Here, we report a case of the same mutant R104C-dependent NDI distinguished from AQP2dependent NDI by responses of factor VIII and $\mathrm{vWF}$ to DDAVP in a middle-aged Japanese man.

\section{Case Report and Methods}

A 47-year-old man was admitted to hospital because of polyuria $(4000 \mathrm{ml} /$ day) pointed out by an urologist. Although the patient had had polyuria and polydipsia from infancy, he had no awareness or symptoms of disease and no medication until admission. At the age of 47 years, hypercreatiniemia (serum creatinine $1.4 \mathrm{mg} / \mathrm{dl}$ ) was discovered on regular check-up, after which hydronephrosis was diagnosed by abdominal echogram as a result of examination for polyuria. His mother's elderly brother aged 85 years, as well as his mother's father who died at the age of 80 years, also had polyuria and polydipsia. His mother aged 75 years, and his first daughter aged 15 years had no symptoms of polyuria and polydipsia, while his second daughter aged 13 years had a mild degree of polyuria and polydipsia (Fig. 1).

On admission, height was measured as $171 \mathrm{~cm}$ and weight $68.3 \mathrm{~kg}$. Blood pressure was $134 / 80 \mathrm{mmHg}$, and pulse rate was regular at $80 / \mathrm{min}$. Body temperature was $36.7^{\circ} \mathrm{C}$. His tongue was dry.

General laboratory data showed sodium concentration, urea nitrogen, creatinine and osmolality in blood to be $148 \mathrm{mEq} / \mathrm{l}, 8.2 \mathrm{mg} / \mathrm{dl}, 1.0 \mathrm{mg} / \mathrm{dl}$ and 295 mosmol $/ \mathrm{kg}$, respectively, while sodium concentration and osmolality in urine were $28 \mathrm{mEql} / \mathrm{l}$ and $94 \mathrm{mosmol} /$ $\mathrm{kg}$, respectively. Urinary volume was 4400 to 8000 $\mathrm{ml} /$ day and intake-volume 3100 to $3800 \mathrm{ml} /$ day. Pyuria was present. CT scanning of the abdomen showed that renal pelvises and urinary tracts were dilated without any organic obstruction and that the bladder wall was thickened.

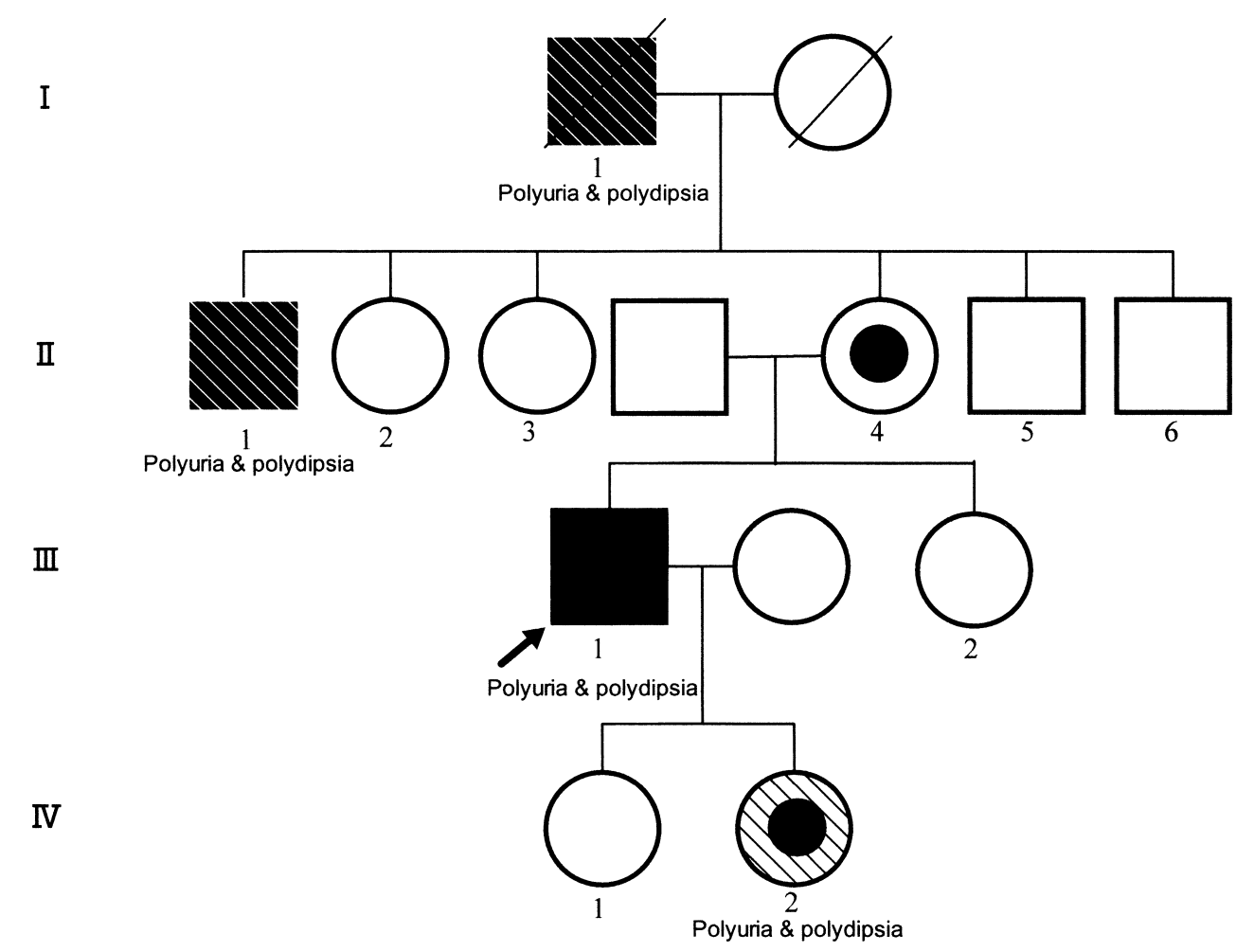

Fig. 1. Pedigree of NDI relatives. Circles, female; squares, men. Roman numerals, the generation. Hatched bar and black symbols, subjects with polyuria and polydipsia. Black symbol, subject for the mutation; circles with a central dot, subject is heterozygotic for one of the mutations. A slash (/) through a symbol indicates that the subject is deceased. The arrow indicates the index case. 
Water deprivation testing resulted in no decrease of urine volume at a $1.6 \%$ decrease of body weight with plasma and urine osmolality being 300 and 283 mosmol $/ \mathrm{kg}$, respectively. Plasma AVP concentrations were 6 to $13 \mathrm{pg} / \mathrm{ml}$. Urinary volume and osmolality did not respond to nasal administration of $10 \mu \mathrm{g}$ of DDAVP.

The DDAVP infusion test was performed following the method of Hochberg et al. [8]. Before DDAVP infusion, a water-load of $600 \mathrm{ml} / \mathrm{m}^{2}$ was given orally to suppress endogenous AVP. Basal urine was collected for an hour. Starting at time zero, DDAVP was infused over $10 \mathrm{~min}$ at a dose of $0.3 \mu \mathrm{g} / \mathrm{kg} \mathrm{BW}$. Urine and blood were collected at 0,60 , and $120 \mathrm{~min}$. Plasma and urine osmolality, factor VIII and vWF factor were measured. Basal levels of factor VIII and vWF factor were $160 \%$ and $110 \%$, respectively. Urine osmolality, factor VIII (160\%) and vWF (108\%), as well as heart rate, diastolic blood pressure and facial flushing after the infusion, failed to respond to DDAVP infusion.

These findings indicated that the patient had V2Rdependent NDI rather than acquired NDI or AQP2dependent NDI. Oral administration of hydrochlorothiazide $50 \mathrm{mg} /$ day and triamterene $100 \mathrm{mg} /$ day decreased urinary volume $(3000 \mathrm{ml} /$ day $)$ with increased osmolality (123 mosmol $/ \mathrm{kg})$.

Mutation analysis of the V2R gene was performed. Informed consent for DNA analysis was obtained from the patient and his family, and was approved by the institutional review board. Genomic DNA was prepared from peripheral leukocytes by standard methods. DNA sequencing was performed as previously described (10). First, the gene was amplified by PCR with oligonucleotide primers (forward: 5'-TGACCA TCCCCTCTCAATCTTC-3'; reverse: 5'-TCCCTCT TTCCTGCACTCCT-3'). Then, nested PCR was performed using the following primers: 5'-CCCAGGAC TGGCCATACTG-3' and 5'-CCAGCTCAGTGAGCT GAC-3'. The $2 \mathrm{~kb}$ PCR product, which covered the exons, the introns, about $140 \mathrm{bp}$ of the $5^{\prime}$-translated region, and about $220 \mathrm{bp}$ of the 3 '-untranslated region of the VR2 gene, was obtained. A total of 12 different primers (sense and antisense) were needed for direct sequencing of the PCR product. Final nested PCR was done with primer 5'-CGGAGCTGGCGCTGCT-3'. Direct sequencing of the PCR product was performed on both strands by an automated DNA sequencer model 373S (Applied Biosystems Japan. Chiba, Japan) using the PRISM dye termination kit (Applied Bio- systems, Chiba, Japan) according to the manufacturer's instructions. The analysis identified a $\mathrm{C}$ to $\mathrm{T}$ transition at nucleotide position +310 in exon 2 , leading to a predicted change of arginine at codon 104 (CGC) to a cysteine (TGC) (Fig. 2) This mutation was the same V2R missense mutation (R104C) located in the first extracellular loop of the V2R as reported by Inaba et al. [9]. Furthermore, the patient's mother and his second daughter aged 13 years were heterozygotic for this mutation (Fig. 2).

\section{Discussion}

This patient was diagnosed with NDI at middle age, although he had had a history of polyuria and polydipsia from infancy. One reason for the delayed recognition of NDI was that he had no awareness of being sick in this respect prior to admission to hospital, since the male members of his family had the same signs and symptoms as he did but without any detrimental effects and no impact on their daily activities.

The main symptoms in patients with hereditary NDI

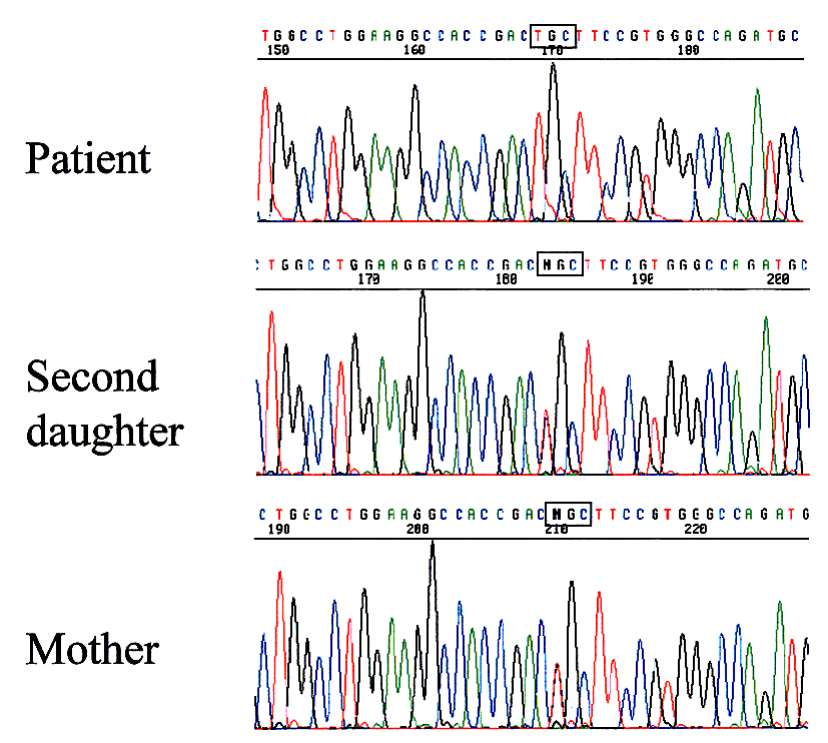

Fig. 2. Direct sequence analysis of AVP receptor 2 (V2R) gene. PCR product was directly sequenced as described in Methods. Direct sequencing of the V2R gene of the patient revealed a missense mutation in the exon 2 at codon 104 (CGC to TGC) (upper panel), resulting in substitution of an arginine with cysteine (R104C). This heterozygous missense mutation was also detected in one allele of the V2R gene of the second daughter (middle panel) and the mother (lower panel). 
are anorexia or vomiting $(70 \%)$, growth disturbance $(50 \%)$, fever $(40 \%)$, constipation $(33 \%)$, polydipsia $(13 \%)$ and mental retardation (3\%) [11]. The patient had no such symptoms. His history indicated the possibility of an inherited X-linked recessive disorder. This suggested that his NDI may have been due to a compromised V2R, because most patients with AQP2dependent NDI have autosomal recessive or autosomal dominant NDI, which is not carried on a sex chromosome. Therefore, males and females are equally likely to inherit it [1]. However, since the patient's second daughter had a mild degree of polyuria and polydipsia, it was difficult to distinguish between the two types of disorders, V2R-dependent NDI and AQP2-dependent NDI, based only on such clinical examinations.

Recently, it has been reported that patients with AQP2-dependent NDI will show responses to DDAVP taking place outside the kidney, while patients whose NDI is dependent on V2R genes will not. The informative parameters are heart rate, diastolic blood pressure and facial flushing as clinical manifestations, and cAMP in blood and urine as a laboratory finding (Table 1). Initially, inherited NDI was divided into two types based on differences in urinary excretion of cAMP after administration of pitressin or DDAVP [2]. Later, it was demonstrated that after infusion of DDAVP, blood levels of cAMP increase in patients with acquired NDI caused by a drug such as lithium [12] or AQP2-dependent NDI, but do not change in patients with V2R-dependent NDI [5]. Recently, it was reported that urinary aquaporin excretion can be detected in patients with V2R-dependent NDI, but neither in patients with AQP2-dependent NDI [13] nor in patients with acquired NDI [14]. However, measurement of cAMP or aquaporin 2 is not practical in the routine setting. The factors which can be easily and accurately measured are tPA, factor VIII and vWF (Table 1). Many reports confirmed that responses of tPA, factor VIII and vWF in blood to DDAVP infusion are normal in NDI caused by an AQP2 mutation and acquired NDI [14] as well as central diabetes insipidus as healthy subjects [16], while there is no response to DDAVP infusion in NDI caused by V2R mutations (Table 1) [1-8]. The patient described here had no medication which caused the acquired NDI and showed no response of factor VIII and vWF blood levels to DDAVP infusion. Accordingly, these results suggested that he had inherited NDI caused by V2R anomaly.

Indeed, molecular genetic analysis demonstrated that the patient had the same V2R missense mutation as reported by Inaba et al. [9]. This mutation involves a substitution of cysteine for arginine at position 104 (R104C), which is located in the first extracellular loop of the V2R. Inaba et al. [9] reported that the $\mathrm{R} 104 \mathrm{C}$ mutation reduces ligand-binding capacity and adenylyl cyclase activity, and that the sulfhydryl group of the cysteine at residue 104 of the mutant receptor is primary responsible for the dysfunction. Furthermore, the patient's mother and his second daughter aged 13 years were heterozygotic for this mutation. This family with an $\mathrm{R} 104 \mathrm{C}$ mutation represents the second reported such occurrence of this type. The first report by Inaba et al. [9] in 2001 was also in a Japanese family.

Table 1. Clinical and laboratory findings on the response to 1-deamino-8D-arginine vasopressin infusion either common to or distinguishing among vasopressin 2 receptor (V2R) dependent-nephrogenic diabetes insipidus (NDI), aquaporin 2 (AQP2)-dependent NDI and acquired NDI in this case.

\begin{tabular}{|c|c|c|c|c|}
\hline & V2R-NDI & AQP2-NDI & Acquired NDI & This case \\
\hline Facial flushing & absent & present & present & absent \\
\hline Heart rate & $\rightarrow$ & $\uparrow$ & $\uparrow$ & $\rightarrow$ \\
\hline Diastolic blood pressure & $\rightarrow$ & $\downarrow$ & $\downarrow$ & $\rightarrow$ \\
\hline \multicolumn{5}{|l|}{ cAMP } \\
\hline Blood & $\rightarrow$ & $\uparrow$ & $\uparrow$ & $?$ \\
\hline Urine & $\rightarrow$ & $\uparrow$ & $\uparrow$ & $?$ \\
\hline Urinary aquaporin 2 & $\rightarrow$ & $\downarrow$ & $\downarrow$ & $?$ \\
\hline Factor VIII & $\rightarrow$ & $\uparrow$ & $\uparrow$ & $\rightarrow$ \\
\hline von Willebrand factor & $\rightarrow$ & $\uparrow$ & $\uparrow$ & $\rightarrow$ \\
\hline $\begin{array}{l}\text { Tissue-type plasminogen } \\
\text { activator antigen }\end{array}$ & $\rightarrow$ & $\uparrow$ & $?$ & $?$ \\
\hline
\end{tabular}

$\rightarrow$ : unchanging, $\downarrow$ : decrease, $\uparrow:$ increased, ?: unknown 
Their patient was also diagnosed at a similar age of 53 years as this case, and the two satellite families are now living at the near places located at Niigata and Fukui prefectures which faced Sea of Japan, respectively, where the distance between the two satellites was about $300 \mathrm{~km}$. Accordingly, the two patients may share common ancestors.

By 2002, 179 mutations of the gene have been recorded worldwide since the first case was reported in 1992 [17]. The inherited NDI in most patients is discovered in the period from infancy to adolescence [17]. These findings suggest that compared with other forms of hereditary V2R-dependent NDI, that caused by the $\mathrm{R} 104 \mathrm{C}$ mutation may not trigger a serious acute outcome but rather slowly progressive disease [17].
Although he had no awareness of being sick, our patient had bilateral non-obstructive hydronephrosis. A review of the literature indicated a strong association between hereditary NDI and non-obstructive hydronephrosis [18]. Accordingly, it is advisable to seek to diagnose and treat inherited NDI as early as possible, even though a clinically-apparent outcome is long-delayed.

In conclusion, we report a case of mutant vasopressin receptor (R104C)-dependent nephrogenic diabetes insipidus with bilateral non-obstructive hydronephrosis distinguished from aquaporin-dependent nephrogenic diabetes insipidus by the responses of factor VIII and von Willebrand factor to 1-deamino-8$\mathrm{D}$-arginine vasopressin in a middle aged man.

\section{Reference}

1. Morello JP, Bichet DG (2001) Nephrogenic diabetes insipidus. Annual Review of Physiology 63: 607-630.

2. Ohzeki T (1985) Urinary adenosine 3',5'-monophosphate (cAMP) response to antidiuretic hormone in diabetes insipidus (DI): comparison between congenital nephrogenic DI type 1 and 2, and vasopressin sensitive DI. Acta Endocrinologica 108: 485-490.

3. Bichet DG, Razi M, Lonergan M, Arthus MF, Papukna V, Kortas C, Barjon JN (1988) Homodynamic and coagulation responses to 1-desamino [8-D-arginine] vasopressin in patients with congenital nephrogenic diabetes insipidus. $N$ Engl J Med 318: 881-887.

4. Bichet DG, Razi M, Arthus MF, Lonergan M, Tittley P, Smiley RK, Rock G, Hirsch DJ (1989) Epinephrine and dDAVP administration in patients with congenital nephrogenic diabetes insipidus. Evidence for a precyclic AMP V2 receptor defective mechanism. Kidney Int 36: 859-866.

5. Brink HS, Derkx FH, Boomsma F, Brommer EJ, Schalekamp MA (1993) 1-Desamino-8-D-arginine vasopressin (DDAVP) in patients with congenital nephrogenic diabetes insipidus. Neth J Med 43: 5-12.

6. van Lieburg AF, Knoers VV, Mallmann R, Proesmans W, van den Heuvel LP, Monnens LA (1996) Normal fibrinolytic responses to 1-desamino-8-D-arginine vasopressin in patients with nephrogenic diabetes insipidus caused by mutations in the aquaporin 2 gene. Nephron 72: 544-546.

7. Vargas-Poussou R, Forestier L, Dautzenberg MD, Niaudet P, Dechaux M, Antignac C (1997) Mutations in the vasopressin $\mathrm{V} 2$ receptor and aquaporin-2 genes in 12 families with congenital nephrogenic diabetes insipidus. J Am Soc Nephrol 8: 1855-1862.

8. Hochberg Z, Van Lieburg A, Even L, Brenner B, Lanir
N, Van Oost BA, Knoers NV (1997) Autosomal recessive nephrogenic diabetes insipidus caused by an aquaporin-2 mutation. J Clin Endocrinol Metab 82: 686689.

9. Inaba S, Hatakeyama H, Taniguchi N, Miyamori I (2001) The property of a novel V2 receptor mutant in a patient with nephrogenic diabetes insipidus. J Clin Endocrinol Metab 86: 381-385.

10. Bichet DG, Arthus MF, Lonergan M, Hendy GN, Paradis AJ, Fujiwara TM, Morgan K, Gregory MC, Rosenthal W, Didwania A, et al. (1993) X-linked nephrogenic diabetes insipidus mutations in north America and the Hopewell hypothesis. J Clin Invest 92: 1262-1268.

11. van Lieburg AF, Knoers VV, Monnens LA (1996) Clinical presentation and follow-up of 30 patients with congenital nephrogenic diabetes insipidus. J Am Soc Nephro 72: 544-546.

12. Waller DG, Albanp JD, Millar JG, Polak A (1983) Impairment of cyclic AMP response to bovine parathyroid hormone in patients on chronic lithium therapy with diminished renal urine-concentrating ability. Clin Sci (Lond) 64: 623-627.

13. Deen PM, van Aubel RA, van Lieburg AF, van Os CH (1996) Urinary content of aquaporin 1 and 2 in nephrogenic diabetes insipidus. J Am Soc Nephrol 7: 836841.

14. Evrard A, Lefebvre J, Vantyghem M (1999) Nephrogenic diabetes insipidus. Ann Endocrinol (Paris) 60: 457-464.

15. Hober C, Vantyghem MC, Racadot A, Cappoen JP, Lefebvre J (1992) Normal homodynamic and coagulation responses to 1-deamino-8-D-arginine vasopressin in a case of lithium-induced nephrogenic diabetes in- 
sipidus. Results of treatment by a prostaglandin synthesis inhibitor (indomethacin). Horm Res 37: 190-195.

16. Moses AM, Miller JL, Levine MA (1988) Two distinct pathophysiological mechanisms in congenital nephrogenic diabetes insipidus. J Clin Endocrinol Metab 66: 1259-1264.

17. Krawczak M, Ball EV, Fenton I, Stenson PD,
Abeysinghe S, Thomas N, Cooper DN (2000) Human gene mutation database-A biomedical information and research resource. Human Mutation 15: 45-51.

18. Uribarri J, Kaskas M (1993) Hereditary nephrogenic diabetes insipidus and bilateral nonobstructive hydronephrosis. Nephron 65: 346-349. 